\title{
The influence of cuttlebone on the target strength of live golden cuttlefish (Sepia esculenta) at 70 and $120 \mathrm{kHz}$
}

\author{
Daejae Lee
}

\begin{abstract}
To quantitatively estimate the influence of cuttlebone on the target strength (TS) of golden cuttlefish, the cuttlebone was carefully extracted from 19 live cuttlefish caught using traps in the inshore waters around Geojedo, Korea, in early May 2010 and the TS was measured using split-beam echosounders (Simrad ES60 and EY500). The TS-length relationships for the cuttlefish (before the extraction of cuttlebone, Fish Aquat Sci. 17:361-7, 2014) and the corresponding cuttlebone were compared. The cuttlebone length $\left(L_{b}\right)$ ranged from 151 to $195 \mathrm{~mm}$ (mean $L_{b}=168.3 \mathrm{~mm}$ ) and the mass $\left(W_{b}\right)$ ranged from 29.3 to $53.2 \mathrm{~g}$ (mean $W_{b}=38.8 \mathrm{~g}$ ). The mean TS values at 70 and $120 \mathrm{kHz}$ were $-33.60 \mathrm{~dB}(\mathrm{std}=1.12 \mathrm{~dB})$ and $-32.24 \mathrm{~dB}(\mathrm{std}=1.87 \mathrm{~dB})$, respectively. The mean $T S$ values of cuttlebone were $0.19 \mathrm{~dB}$ and $0.04 \mathrm{~dB}$ lower than those of cuttlefish at 70 and $120 \mathrm{kHz}$, respectively. For 70 and $120 \mathrm{kHz}$ combined, the mean TS value of cuttlebone was $-32.87 \mathrm{~dB}, 0.11 \mathrm{~dB}$ lower than that of cuttlefish $(-32.76 \mathrm{~dB})$. On the other hand, the mean TS value of cuttlebone predicted by the regression $\left(T S_{b}=24.86 \log _{10}\right.$ $\left.L_{b}-4.86 \log _{10} \lambda-22.58, r^{2}=0.85, N=38, P<0.01\right)$ was $-33.10 \mathrm{~dB}, 0.04 \mathrm{~dB}$ lower than that of cuttlefish predicted by the regression $\left(T S_{C}=24.62 \log _{10} L_{C}-4.62 \log _{10} \lambda-22.64, r^{2}=0.85, N=38, P<0.01\right)$. That is, the contribution of cuttlebone to the cuttlefish TS determined by the measured results was slightly greater than that by the predicted results. These results suggest that cuttlebone is responsible for the TS of cuttlefish, and the contribution is estimated to be at least $99 \%$ of the total echo strength.
\end{abstract}

Keywords: Sepia esculenta Target strength, Influence of cuttlebone, Tilt angle, Length dependence

\section{Background}

Most aquatic animals, such as swimbladder fish and cuttlefish, maintain their depth in the sea by adjusting their average density to equal that of seawater using gas-filled organs that serve as a buoyancy tank (Denton and Gilpin-Brown 1961; Denton et al. 1961; Denton and Taylor 1964). These aquatic animals use essentially the same mechanism in their swimbladders and cuttlebones to achieve the buoyancy control needed to minimize energy consumption (Midtvedt et al. 2007). If the body density is higher than the surrounding water, the animal sinks. Similarly, aquatic animals of lower density float towards the surface. As long as the aquatic animal is not moving, this task is fairly simple, but aquatic animals move and as soon as the animal ascends or descends, the hydrostatic pressure changes. In swimbladder

Correspondence: daejael@pknu.ac.kr

Division of Marine Production System Management, Pukyong National University, Busan 48513, Korea fish, to compensate for this, gas must be rapidly secreted into the swimbladder while descending and removed while ascending (Denton and Gilpin-Brown 1961; Denton et al. 1961; Denton and Taylor 1964; Fnney et al. 2006). However, in cuttlefish, such problems of pressure change are avoided by enclosing the gas inside an incompressible chamber within the cuttlebone, the volume of which is unaffected by depth, and so cuttlefish maintain neutral buoyancy almost independent of depth (Sherrard 2000). Thus, the buoyancy mechanisms used by cuttlefish and swimbladder fish differ. The cuttlebone of cuttlefish comprises $\sim 9 \%$ of total body volume, but the swimbladder of fish only $4-6 \%$ of total body volume (Denton and Gilpin-Brown 1961; Denton et al. 1961; Denton and Taylor 1964; Webber et al. 2000; Horne 2008; Sunardi et al. 2008). Foote et al. (Foote 1980a, 1980b, 1985; Foote and Ona 1985) indicated that the swimbladder is responsible for more than $90 \%$ of the reflected sound energy from a fish. These facts suggest that the 
contribution of cuttlebone to the TS of cuttlefish may be larger than that of the swimbladder to the TS of fish, if the volume of cuttlebone does not change with depth. Other than our earlier study (Lee and Demer 2014), there has been no systematic attempt to determine the relationship between the TS and size of cuttlefish, especially the importance of cuttlebone to cuttlefish TS.

The objective of this study was to estimate the influence of cuttlebone on the TS of golden cuttlefish (Sepia esculenta), by comparing the TS- $L$ relationships for cuttlebone and cuttlefish at 70 and $120 \mathrm{kHz}$.

\section{Methods}

\section{Echosounders and calibrations}

The acoustic and mechanical system for measuring the TS of cuttlebone is shown in Fig. 1 (Lee and Demer 2014). It comprised two split-beam echosounders (ES60 and EY500, Simrad, Norway) operating at 70 and $120 \mathrm{kHz}$, two split-beam transducers (half-power beamwidths $=11^{\circ}$ and $7.1^{\circ}$, respectively) and a DC servomotor system (motor: BG90, Sung Shin, Korea; driver: KDC248H, KScontrol, Korea) to control the tilt angles of the cuttlebone during each acoustic transmission. A watercooling system maintained the seawater at a temperature $T=18.0{ }^{\circ} \mathrm{C}$ (confirmed by measurements before and near the end of the experiment). The two transducers were mounted adjacently facing sidewards, with the center of their faces at approximately $56 \mathrm{~cm}$ below the water surface.

Before and near the end of the experiments, the 70 and $120 \mathrm{kHz}$ echosounders were calibrated using copper spheres of 32.1 and $23.0 \mathrm{~mm}$ diameter, respectively. The TS measurements were corrected for these calibrated offsets $(-0.3 \mathrm{~dB}$ at $70 \mathrm{kHz}$ and $0.5 \mathrm{~dB}$ at $120 \mathrm{kHz})$.

The experiment was conducted under the guidelines of Animal Ethics Committee Regulations, No. 554 issued from Pukyong National University, Busan, Korea. Nineteen cuttlebones directly extracted from 19 of the 23 live cuttlefish individuals (with the exception of four broken cuttlebones) tested in our earlier study (Lee and Demer 2014) were used as specimens for the TS measurements. Each cuttlebone was carefully extracted from each live cuttlefish specimen in sea water just before the experiment, and then immediately moved to a small tank filled with seawater at $18{ }^{\circ} \mathrm{C}$.

To avoid variations in the acoustic and physical properties of the extracted cuttlebone with time, especially due to changes in shape, structure, chamber space and density, the cuttlebone TS measurement was rapidly performed under almost identical conditions, but in another acrylic salt-water tank, following measurement of the TS of live cuttlefish.

Before each set of measurements, the specimen was carefully suspended into the overlapping sound beams, avoiding the introduction of air bubbles. The tilt angle

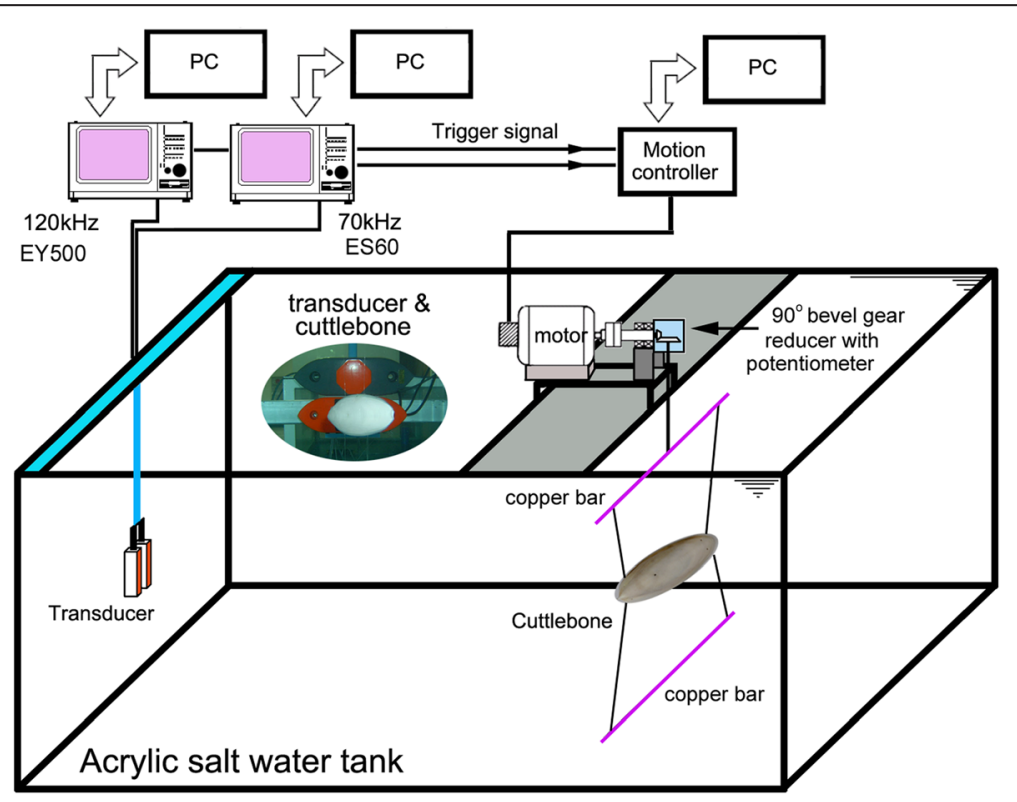

Fig. 1 Diagram of the acoustic-mechanical apparatus used to measure cuttlebone target strength (TS) versus length $\left(L_{b}\right)$, and tilt angle $(\theta)$. The apparatus comprise: a rectangular (1.2 width $\times 1.8$ length $\times 1.2 \mathrm{~m}$ height), acrylic, saltwater tank; 70 and $120 \mathrm{kHz}$ echosounders (Simrad ES60 and EY500, respectively); two split-beam transducers (Simrad ES70-11 and ES120-7 F, respectively); and a DC servo-motor system for controlling the tilt angle of cuttlebone. The cuttlebone was slowly rotated for the angle range of $-90^{\circ}$ (head-down orientation) to $90^{\circ}$ (head-up orientation) at a fixed speed of $0.167 \mathrm{rpm}$ and stably maintained by tying monofilament lines between both ends of cuttlebone and two horizontal bars for suspending 
of the cuttlebone was controlled using four monofilament lines $(0.2 \mathrm{~mm}$ diameter), each tied to the anterior (head) and posterior (spine) parts of the cuttlebone, at both ends of an upper copper bar connected to the rotating axis of a DC servomotor system, and at both ends of a lower copper bar acting as a balancing weight (Fig. 1). The tilt angle was measured using a precision potentiometer (CP50, Sakae Tsushin Kogyo, Japan) connected to the axis of a $90^{\circ}$ bevel gear reducer (ratio 240:1). The rotation speed of the cuttlebone was controlled by changing the input voltage of the DC servomotor system.

The definition of tilt angle for cuttlebone is shown in Fig. 2. The precise dorsal aspect of cuttlebone relative to the axis of the transducer was defined as a tilt angle of $0^{\circ}$, and the head up and down orientations relative to the center line of the cuttlebone were defined as positive $\theta$ and negative $\theta$ values, respectively.

In each case, the range between the transducers and the cuttlebone was approximately $1.2 \mathrm{~m}$. The far-field ranges for the 70 and $120 \mathrm{kHz}$ transducers (diameter $d=13.5$ and $12.9 \mathrm{~cm}$ ) were $\sim 0.47$ and $\sim 0.68 \mathrm{~m}$ (Lee 2006; Foote 2012), respectively. During the calibrations and the TS measurements, the 70 and $120 \mathrm{kHz}$ echosounders transmitted 300 and $60 \mathrm{~W}$ pulses with durations of $256 \mu$ s and $300 \mu \mathrm{s}$ every $0.2 \mathrm{~s}$, and received the echoes using 6.2 and $12 \mathrm{kHz}$ receiver bandwidths, respectively. The experiments in all cases were conducted using the same pulse duration, transmit power, pulse repetition interval and bandwidth used during the TS measurement of the calibration sphere. To avoid crosstalk, the measurements at 70 and $120 \mathrm{kHz}$ were taken sequentially. When the trigger pulse of the echosounder was transferred to a PC-based motor controller (ComiSD501, Comizoa, Korea) and signal processor (ComiLX102, Comizoa, Korea), the TS measurement for the cuttlebone rotating at a fixed speed of $0.167 \mathrm{rpm}$, from the head-down orientation $\left(-90^{\circ}\right)$ to the head-up orientation $\left(+90^{\circ}\right)$, was conducted continuously. The output voltage of the precision potentiometer corresponding to the tilt angle and the echo data were recorded simultaneously and later processed to estimate the relationship between TS and tilt angle $(\theta)$ during each transmission. The echo data, logged by the echosounders, were post-processed using commercial software (Echoview V3.3, Sonar Data, Australia; EP500 v. 5.2, Simrad, Norway).

\section{Specimens and measurement of target strength}

The biological and morphological characteristics of 19 specimens of cuttlebone and the corresponding live cuttlefish (Lee and Demer 2014) used in the TS experiments are shown in Table 1 . These characteristics-such as length, weight, width and thickness-were measured following completion of the acoustic experiments. Mantle length $\left(L_{c}\right)$ and body mass $\left(W_{c}\right)$ for cuttlefish ranged from 156 to $203 \mathrm{~mm}$ (mean $L_{c}=173.9$; deviation $(\mathrm{std})=$ $13.10 \mathrm{~mm}$ ) and $335-720 \mathrm{~g}$ (mean $W_{c}=527.4 ; \quad$ std $=$ $104.4 \mathrm{~g})$, respectively. The length $\left(L_{b}\right)$, weight $\left(W_{b}\right)$, width $\left(W_{d}\right)$ and thickness $\left(T_{h}\right)$ of cuttlebone ranged from 151 to $195 \mathrm{~mm}$ (mean $L_{b}=168.3$; std $=12.56 \mathrm{~mm}$ ), 29.3-53.2 g (mean $W_{b}=38.8$; std $\left.=7.23 \mathrm{~g}\right), 55-69 \mathrm{~mm}\left(\right.$ mean $W_{d}=$ 62.4; $\mathrm{std}=4.10 \mathrm{~mm})$, and $13.6-18.0 \mathrm{~mm}\left(\right.$ mean $T_{h}=15.7$; $\mathrm{std}=1.24 \mathrm{~mm})$, respectively.

The mean tilt angles $(<\theta>)$ with standard deviations $\left(S_{\theta}\right)$ measured for 19 live cuttlefish at 70 and $120 \mathrm{kHz}$ in our earlier study (Lee and Demer 2014) are shown in Table 2. The TS and $\theta$ for these live cuttlefish were measured simultaneously using a split-beam echo sounder and a CCTV camera system, respectively and the $(<\theta>)$ and $S_{\theta}$ values were used in estimating the tilt-averaged TS from the TS functions of the corresponding cuttlebone.

In the $70 \mathrm{kHz}$ experiments, the mean tilt angles of 19 live cuttlefish varied from $-3.51^{\circ}$ to $-1.05^{\circ}$ (mean $-2.31^{\circ}$,

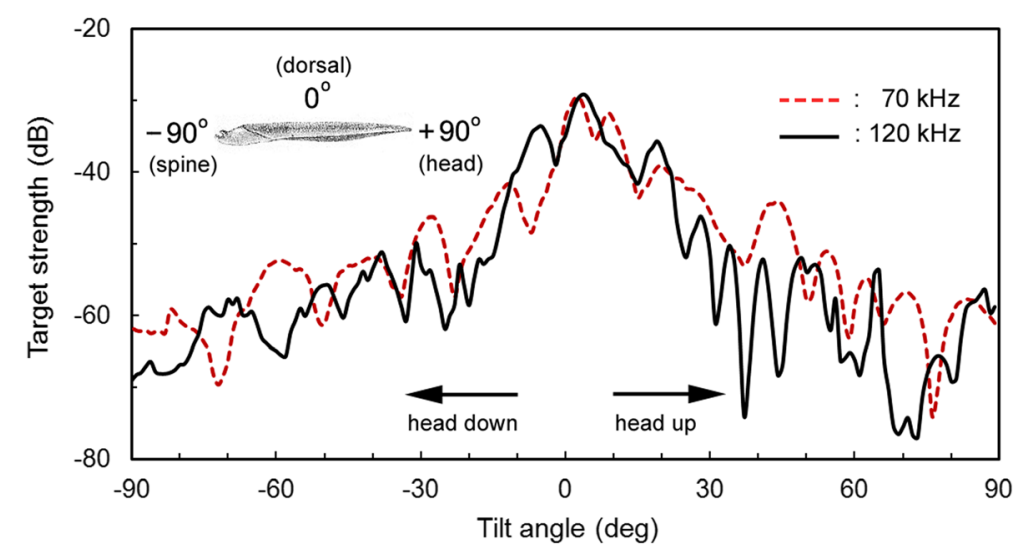

Fig. 2 Comparison of the TS functions for cuttlebone $\left(L_{b}=15.2 \mathrm{~cm}, W_{b}=29.3 \mathrm{~g}\right)$ measured as a function of tilt angle at 70 (dash line) and $120 \mathrm{kHz}$ (solid line). The precise dorsal-aspect orientation is defined by the angle $0^{\circ}$, and the precise head-down and head-up orientations are defined by angles $-90^{\circ}$ and $90^{\circ}$, respectively 
Table 1 Biological characteristics of the corresponding cuttlebone and the body of 19 live cuttlefishes used in the TS measurements

\begin{tabular}{|c|c|c|c|c|c|c|}
\hline \multirow{2}{*}{$\begin{array}{l}\text { Specimen } \\
\text { No. }\end{array}$} & \multicolumn{2}{|l|}{ Cuttlefish } & \multicolumn{4}{|l|}{ Cuttlebone } \\
\hline & Length $^{\mathrm{a}}(\mathrm{mm})$ & Weight (g) & Length $(\mathrm{mm})$ & Weight (g) & Width $(\mathrm{mm})$ & Thickness (mm) \\
\hline 1 & 194 & 550 & 185 & 41.2 & 63.0 & 14.8 \\
\hline 2 & 176 & 435 & 172 & 41.6 & 61.4 & 15.6 \\
\hline 3 & 165 & 520 & 159 & 31.9 & 68.0 & 14.3 \\
\hline 4 & 178 & 510 & 173 & 39.0 & 66.7 & 16.8 \\
\hline 5 & 182 & 643 & 175 & 47.9 & 64.4 & 16.4 \\
\hline 6 & 174 & 565 & 169 & 33.4 & 61.0 & 15.1 \\
\hline 7 & 164 & 370 & 155 & 37.4 & 58.1 & 18.0 \\
\hline 8 & 176 & 512 & 171 & 45.3 & 68.0 & 16.4 \\
\hline 9 & 158 & 335 & 152 & 29.3 & 59.8 & 14.9 \\
\hline 10 & 203 & 720 & 195 & 47.9 & 66.0 & 17.2 \\
\hline 11 & 161 & 475 & 158 & 31.3 & 55.0 & 13.6 \\
\hline 12 & 156 & 450 & 151 & 31.8 & 59.0 & 15.0 \\
\hline 13 & 166 & 420 & 161 & 33.6 & 62.9 & 15.5 \\
\hline 14 & 172 & 530 & 166 & 35.9 & 63.2 & 15.3 \\
\hline 15 & 177 & 645 & 173 & 48.8 & 62.0 & 16.6 \\
\hline 16 & 176 & 675 & 173 & 42.4 & 59.3 & 17.8 \\
\hline 17 & 197 & 645 & 191 & 53.2 & 69.0 & 16.4 \\
\hline 18 & 160 & 475 & 155 & 30.1 & 55.0 & 13.9 \\
\hline 19 & 169 & 545 & 163 & 35.1 & 63.0 & 15.5 \\
\hline mean & 173.9 & 527.4 & 168.3 & 38.8 & 62.4 & 15.7 \\
\hline
\end{tabular}

${ }^{a}$ The length of cuttlefish is a dorsal mantle length

head-down), while the standard deviation varied from $2.32^{\circ}$ to $12.64^{\circ}$ (mean $6.56^{\circ}$ ). At $120 \mathrm{kHz}$, the mean tilt angles varied from $-5.11^{\circ}$ to $-0.73^{\circ}$ (mean $-3.15^{\circ}$ ), while the standard deviation varied from $2.33^{\circ}$ to $6.86^{\circ}$ (mean $4.74^{\circ}$ ).

\section{Target strength models}

To compare the TS of cuttlebone with that of live cuttlefish, two TS values, such as the maximum $T S\left(T S_{m}\right)$ and the tilt-averaged $T S\left(\left\langle T S_{b}\right\rangle\right)$ in the dorsal-aspect orientation of the cuttlebone, were estimated. First, the $T S_{m}$ was obtained directly from the measured TS functions. Next, the $<T S_{b}>$ was calculated by using the probability density function $f(\theta)$ of tilt angle $\theta$, with mean $\theta(<\theta>)$ and standard deviation $S_{\theta}$, according to Eqs. (1) and (2) (Foote 1980a, 1980b; Pena and Foote 2008):

$$
\begin{aligned}
& <\sigma>=\int \sigma(\theta) f(\theta) d \theta \\
& <T S_{b}>=10 \log (<\sigma>/ 4 \pi)
\end{aligned}
$$

where $\theta$ is the tilt angle defined as the angle made by the cuttlebone centerline with the horizontal, $\sigma(\theta)$ is the backscattering cross section of tilt angle $\theta$ and the tiltangle distribution $f(\theta)$ was assumed to be a truncated normal distribution function. For each cuttlebone, the $\left\langle T S_{b}\right\rangle$ was computed over the range $<\theta>-3 S_{\theta}$ to $<\theta>+3 \quad S_{\theta}$ using the mean tilt angle $(<\theta>)$ with standard deviation $\left(S_{\theta}\right)$ indicated in Table 2.

Each dataset of the mean TS of cuttlebone and cuttlefish obtained for 19 specimens at 70 and $120 \mathrm{kHz}$ was regressed on specimen length $L$ and wavelength $\lambda$ according to the empirical equation. First, to establish empirical single-frequency relationships between the $\langle T S\rangle$ and the corresponding $L$, the dataset for each frequency was independently fit, in the least-squares sense, to (Benoit-Bird et al. 2008; Conti and Demer. 2003; Demer and Martin 1995; Foote 1987; Goddard and Welsby 1986; Imaizumi et al. 2008; Kang et al. 2005; Sawada et al. 2011):

$$
T S=m \log _{10} L+b
$$

where $L$ is the specimen length $(\mathrm{cm}), m$ is the slope of the regression line, and $b$ is the intercept of the regression line on the TS axis.

Next, the datasets from both frequencies were combined to obtain a relationship for a wider range of specimen lengths $(L)$ and wavelengths $(\lambda)$ : 
Table 2 Mean tilt angles $(\langle\theta\rangle)$ with standard deviations $\left(S_{\theta}\right)$ used in estimating the mean TS of cuttlebone at 70 and $120 \mathrm{kHz}$ (Lee and Demer 2014). The TS and $\theta$ for live cuttlefish were simultaneously measured by a split-beam echo sounder and a CCTV system, respectively

\begin{tabular}{|c|c|c|c|c|c|c|}
\hline \multirow{2}{*}{$\begin{array}{l}\text { Specimen } \\
\text { No. }\end{array}$} & \multicolumn{3}{|l|}{$70 \mathrm{kHz}$} & \multicolumn{3}{|l|}{$120 \mathrm{kHz}$} \\
\hline & M. tilt angle (deg) & Standard dev. (deg) & $N$ & M. tilt angle (deg) & Standard dev. (deg) & $N$ \\
\hline 1 & -3.08 & 12.64 & 14 & -3.15 & 3.27 & 16 \\
\hline 2 & -1.71 & 6.21 & 15 & -3.01 & 5.46 & 15 \\
\hline 3 & -2.96 & 7.39 & 15 & -4.77 & 6.23 & 15 \\
\hline 4 & -3.01 & 9.19 & 15 & -2.01 & 2.93 & 15 \\
\hline 5 & -2.29 & 2.32 & 15 & -2.29 & 2.33 & 15 \\
\hline 6 & -1.93 & 3.83 & 15 & -3.03 & 4.99 & 15 \\
\hline 7 & -1.75 & 5.41 & 15 & -4.23 & 6.45 & 15 \\
\hline 8 & -2.71 & 9.61 & 14 & -4.87 & 3.91 & 14 \\
\hline 9 & -2.71 & 5.99 & 15 & -3.25 & 5.49 & 15 \\
\hline 10 & -1.17 & 3.37 & 15 & -5.11 & 4.10 & 15 \\
\hline 11 & -2.39 & 5.28 & 15 & -4.61 & 5.76 & 15 \\
\hline 12 & -1.05 & 6.76 & 15 & -2.37 & 5.67 & 15 \\
\hline 13 & -3.51 & 8.52 & 15 & -4.55 & 4.46 & 15 \\
\hline 14 & -1.21 & 3.63 & 15 & -0.73 & 5.24 & 15 \\
\hline 15 & -1.91 & 6.84 & 15 & -2.39 & 3.03 & 15 \\
\hline 16 & -1.71 & 6.44 & 15 & -1.43 & 5.56 & 15 \\
\hline 17 & -3.27 & 6.53 & 15 & -2.77 & 6.86 & 15 \\
\hline 18 & -2.97 & 6.17 & 15 & -3.07 & 4.71 & 15 \\
\hline 19 & -2.61 & 8.56 & 15 & -2.13 & 3.68 & 15 \\
\hline mean & -2.31 & 6.56 & & -3.15 & 4.74 & \\
\hline
\end{tabular}

$$
T S=a \log _{10} L+b \log _{10} \lambda+c
$$

where $L$ is the specimen length $(\mathrm{m}), \lambda$ is the acoustic wavelength (m), and $a, b, c$ are the fitted coefficients (Love 1969, 1971; McClatchie et al. 1996, 2003).

The mean TS $\left.\left(<T S_{c}\right\rangle\right)$ of live cuttlefish was derived from the results of TS measurements of the same specimen listed in Table 1 and described fully in our earlier study (Lee and Demer 2014). The influence of cuttlebone on the cuttlefish $T S\left(\left\langle T S_{c}\right\rangle\right)$ was analyzed by estimating the difference between these mean TS values and by comparing the TS-length relationships for the corresponding cuttlebone and the cuttlefish at 70 and $120 \mathrm{kHz}$.

\section{Results}

The $<T S_{b}>$ of 19 cuttlebones were plotted separately for 70 and $120 \mathrm{kHz}$ versus cuttlebone length $L_{b}$, overlaid on the regressions of Eq. (3) (Figs. 3 and 4).

At $70 \mathrm{kHz}$,

$$
\begin{aligned}
& T S=22.03 \log _{10}\left(L_{b} \text { incm }\right)-60.72 \\
& \left(r^{2}=0.40, N=19, P<0.01\right)
\end{aligned}
$$

At $120 \mathrm{kHz}$,

$$
\begin{aligned}
& T S=28.53 \log _{10}\left(L_{b} \text { in cm }\right)-67.55 \\
& \left(r^{2}=0.24, N=19, P<0.05\right) .
\end{aligned}
$$

The mean $<T S_{b}>$ at $70 \mathrm{kHz}$ was $-33.60 \mathrm{~dB}, 1.36 \mathrm{~dB}$ lower than that at $120 \mathrm{kHz}(-32.24 \mathrm{~dB})$. The mean $\left\langle T S_{b}\right\rangle$ at $70 \mathrm{kHz}$ was $0.30 \mathrm{~dB}$ higher than that indicated by Eq. (5) and the mean $<T S_{b}>$ at $120 \mathrm{kHz}$ was $0.33 \mathrm{~dB}$ higher

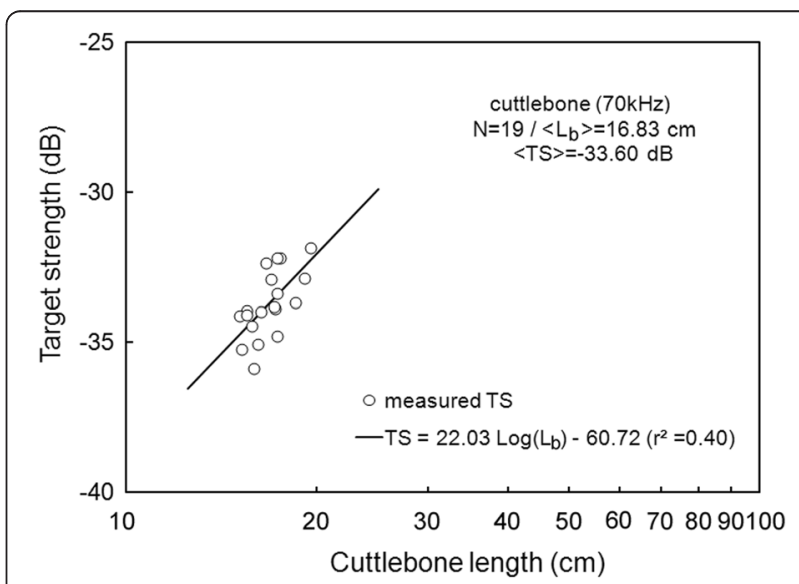

Fig. 3 Relationship between mean $\left.T S\left(<T S_{b}\right\rangle\right)$ and cuttlebone length $\left(L_{b}\right)$ at $70 \mathrm{kHz}$ for 19 cuttlebones extracted from cuttlefish caught during the spawning season in the southwest waters of Korea 


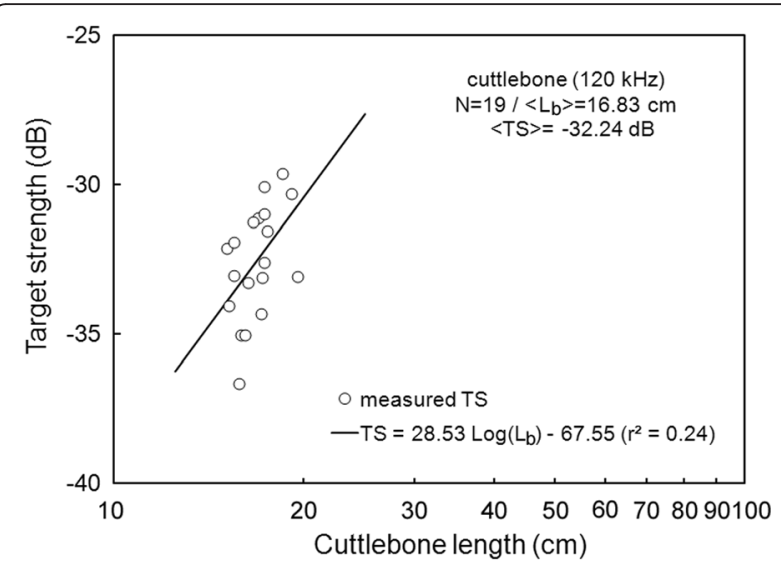

Fig. 4 Relationship between mean $T S\left(\left\langle T S_{b}\right\rangle\right)$ and cuttlebone length $\left(L_{b}\right)$ at $120 \mathrm{kHz}$ for 19 cuttlebones extracted from cuttlefish caught during the spawning season in the southwest waters of Korea

than that indicated by Eq. (6). The difference between the slopes of the regressions for these frequencies was 6.5 , and the intercept at $70 \mathrm{kHz}$ was $6.83 \mathrm{~dB}$ higher than that at $120 \mathrm{kHz}$ (Eqs. 5 and 6).

For 70 and $120 \mathrm{kHz}$ combined, the 38 measurements of $<T S_{b}>$ and $T S_{m}$ were transformed to mean scattering cross-sectional areas $\left(\sigma ; \mathrm{m}^{2}\right)$ and $\sigma^{2} / \lambda$ was plotted versus $L / \lambda$ (Fig. 5). In Fig. 5, the $T S_{m}$ in the dorsal-aspect orientation of cuttlebone was derived by simple extraction from the TS function measured as a function of tilt angle. The mean $T S\left(\left\langle T S_{c}\right\rangle\right)$ of live cuttlefish was obtained from the results of TS measurements of the

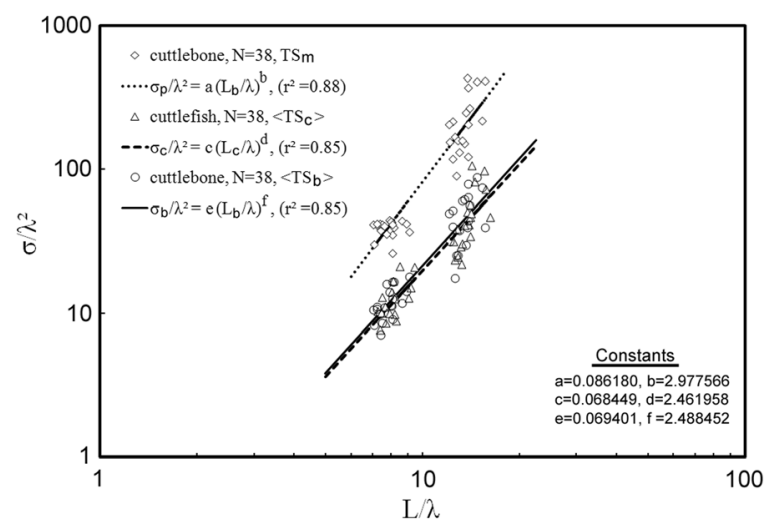

Fig. 5 Comparison of the relationships between $\sigma / \lambda^{2}$ and $L / \lambda$ for each dataset of cuttlebone and cuttlefish (Lee and Demer 2014) obtained by combining $120 \mathrm{kHz}$ data (Fig. 4) with $70 \mathrm{kHz}$ data (Fig. 3), where $\sigma_{p}, \sigma_{b}$ and $\sigma_{c}$ are scattering cross-sectional areas $\left(\mathrm{m}^{2}\right)$ corresponding to the maximum $T S\left(T S_{m}\right)$ and the mean $T S\left(\left\langle T S_{b}\right\rangle\right)$ of cuttlebone, and the mean TS $\left(\left\langle T S_{C}\right\rangle\right)$ of cuttlefish, respectively. $L_{b}$ and $L_{c}$ is the lengths $(m)$ of cuttlebone and cuttlefish, respectively and $\lambda$ is the acoustic wavelength (m). The TS- $L$ relationships for cuttlebone and cuttlefish was converted from the relationships between $\sigma / \lambda^{2}$ and $L / \lambda$, respectively specimens listed in Table 1 and described fully in our earlier study (Lee and Demer 2014).

In this wavelength-normalized form, the $T S_{m},\left\langle T S_{b}\right\rangle$, and $\left\langle T S_{c}>\right.$ values of cuttlebone are comparable between frequencies:

$$
\begin{aligned}
\sigma_{p} / \lambda^{2} & =0.086180\left(L_{b} / \lambda\right)^{2.977566} \\
\left(r^{2}\right. & =0.88, N=38, \quad P<0.01)
\end{aligned}
$$

for $T S_{m}$

$$
\begin{aligned}
\sigma_{b} / \lambda^{2} & =0.069401\left(L_{b} / \lambda\right)^{2.486144} \\
\left(r^{2}\right. & =0.85, N=38, \quad P<0.01)
\end{aligned}
$$

for $\left\langle T S_{b}\right\rangle$, and

$$
\begin{aligned}
\sigma_{c} / \lambda^{2} & =0.068449\left(L_{c} / \lambda\right)^{2.461958} \\
\left(r^{2}\right. & =0.85, N=38, \quad P<0.01)
\end{aligned}
$$

for $\left\langle T S_{c}\right\rangle$, where $\sigma_{p}, \sigma_{b}$, and $\sigma_{c}$ are scattering crosssectional areas $\left(\mathrm{m}^{2}\right)$ corresponding to the $T S_{m}$ and $\left\langle T S_{b}\right\rangle$ of cuttlebone and the $<T S_{c}>$ of cuttlefish, respectively.

Using Eq. (4), the predicted TS's of an individual specimen of cuttlebone and cuttlefish are indicated by:

$$
T S_{p}=29.78 \log _{10} L_{b}-9.78 \log _{10} \lambda-21.64
$$

for the predicted value $\left(T S_{p}\right)$ of $T S_{m}$,

$$
T S_{b}=24.86 \log _{10} L_{b}-4.86 \log _{10} \lambda-22.58
$$

for the predicted value $\left(T S_{b}\right)$ of $<T S_{b}>$, and

$$
T S_{c}=24.62 \log _{10} L_{c}-4.62 \log _{10} \lambda-22.64
$$

for the predicted value $\left(T S_{c}\right)$ of $\left\langle T S_{c}\right\rangle$, where $L_{b}$ and $L_{c}$ are the length of cuttlebone $(\mathrm{m})$ and the mantle length of cuttlefish $(\mathrm{m})$, respectively and $\lambda$ is the wavelength $(\mathrm{m})$.

The mean $T S_{m}$ values were $-28.45 \mathrm{~dB}$ at $70 \mathrm{kHz}$ and $-25.59 \mathrm{~dB}$ at $120 \mathrm{kHz}$, respectively. These mean $T S_{m}$ values were $0.09 \mathrm{~dB}$ at $70 \mathrm{kHz}$ and $0.71 \mathrm{~dB}$ at $120 \mathrm{kHz}$ higher than those predicted by Eq. (10). The mean $\left\langle T S_{b}\right\rangle$ values were $-33.60 \mathrm{~dB}$ at $70 \mathrm{kHz}$ and $-32.24 \mathrm{~dB}$ at $120 \mathrm{kHz}$. These mean $\left\langle T S_{b}>\right.$ values were $0.11 \mathrm{~dB}$ at $70 \mathrm{kHz}$ and $0.33 \mathrm{~dB}$ at $120 \mathrm{kHz}$ higher than those predicted by Eq. (11). The differences between the mean $T S_{m}$ and the mean $<T S_{b}>$ were $5.14 \mathrm{~dB}$ at $70 \mathrm{kHz}$ and $6.65 \mathrm{~dB}$ at $120 \mathrm{kHz}$. The mean $<T S_{c}>$ values were $-33.41 \mathrm{~dB}$ at $70 \mathrm{kHz}$ and $-32.20 \mathrm{~dB}$ at $120 \mathrm{kHz}$. These mean $\left\langle T S_{c}>\right.$ values were $0.23 \mathrm{~dB}$ at $70 \mathrm{kHz}$ and $0.35 \mathrm{~dB}$ at $120 \mathrm{kHz}$ higher than that predicted by Eq. (12). Furthermore, for 70 and $120 \mathrm{kHz}$ combined, the mean $<T S_{c}>$ value was $-32.86 \mathrm{~dB}, 0.11 \mathrm{~dB}$ higher than the mean $<T S_{b}>$ value $(-32.87 \mathrm{~dB})$. On the other hand, the mean $\left\langle T S_{c}\right\rangle$ 
predicted by Eq. (12) was $-33.06 \mathrm{~dB}, 0.04 \mathrm{~dB}$ higher than the mean $<T S_{b}>$ predicted by Eq. $(11)(-33.10 \mathrm{~dB})$.

Accordingly, the contribution of cuttlebone to cuttlefish TS determined by the predicted results was slightly larger than that by the measured results. These results suggest that the cuttlebone is fully responsible for the TS of cuttlefish and the contribution is estimated to be more than $99 \%$ of the total echo strength.

\section{Discussion}

An example of the 70 and $120 \mathrm{kHz}$ echograms recorded as a function of tilt angle, as the cuttlebone is rotated from the spine-on aspect $\left(-90^{\circ}\right)$ toward the broadside incidence of the dorsal surface in the pitch plane, is shown in Fig. 5. At spine-on and head-on aspects, there was very weak scattering, and as the cuttlebone was approached from the spine-on aspect toward the broadside orientation, the scattering gradually increased. These angular and frequency dependences of acoustic scattering may allow the cuttlefish to be distinguishable from other fish species, which may be expected to have different responses at these frequencies. In particular, the angular dependence on the backscattering in the dorsal plane of the cuttlebone must be accounted for in relation to the improvement of the fish-sizing accuracy of split-beam echo sounders operating at these frequencies. It is also important to note that the tilt-angle dependence of the echo response in Fig. 6 is extremely complex due to the constructive and destructive interference effects of the backscattering signals generated by internal cuttlebone chambers.

In our previous study (Lee and Demer 2014), the orientation for freely swimming cuttlefish was slightly

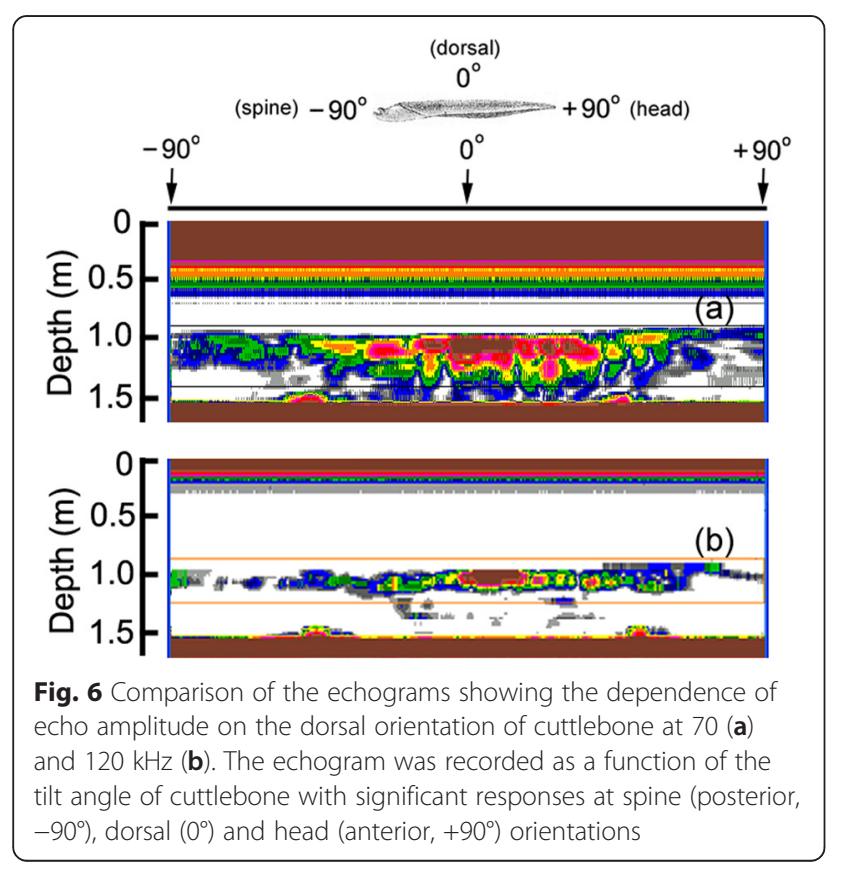

angled head-down relative to the medial axis of the cuttlefish. The strongest backscattering in Fig. 6 was predicted to occur when the cuttlebone surface closest to the sound source is orthogonal to the transducer. However, because of the complexity of the chamber structure, density and curvature of the dorsal surface, the strong echo amplitudes in the echograms for 70 and $120 \mathrm{kHz}$ occurred at slightly head-up aspects (positive tilt-angles).

The measured TS functions, interpolated at $1^{\circ}$ intervals, for 70 and $120 \mathrm{kHz}$ are shown in Figs. 7 and 8, respectively; the tilt-averaged TS functions for all 19 cuttlebones were overlaid on the plot. In Figs. 7 and 8, a positive tilt angle indicates a head-up posture and a negative tilt angle indicates a head-down posture. The strongest responses were observed at slightly head-up aspects between $1^{\circ}$ and $14^{\circ}$ at $70 \mathrm{kHz}$ and between $2^{\circ}$ and $10^{\circ}$ at $120 \mathrm{kHz}$, and weak responses of approximately $-60 \mathrm{~dB}$ were observed near the spine-on $\left(-90^{\circ}\right.$ aspect) and head-on $\left(+90^{\circ}\right.$ aspect) orientations.

For each cuttlebone, these measured TS functions were used to calculate the mean TS over the range $[\langle\theta\rangle$ $\left.-3 S_{\theta},<\theta>+3 S_{\theta}\right]$ from head-down to head-up orientations by Foote's method (Foote 1980a, 1980b; Pena and Foote 2008). A comparison of the tilt-averaged TS functions of cuttlebone at 70 and $120 \mathrm{kHz}$ is shown in Fig. 9. The tilt-averaged TS function for $120 \mathrm{kHz}$ showed a strong directivity pattern with higher, narrower peaks and deeper nulls than for $70 \mathrm{kHz}$, and these TS patterns were essentially unimodal with the dominant peaks at slightly positive aspects; the tails in the anterior and posterior orientations extended down to $\sim 60 \mathrm{~dB}$. It appeared that the tilt-averaged TS function for $120 \mathrm{kHz}$ exhibited a wider pattern near the peak than at $70 \mathrm{kHz}$ (Fig. 9), but the broadening was due to the overlapping of TS patterns with different tilt angles for the peak positions (Figs. 7 and 8). The peak TS values in the tiltaveraged TS functions were $-29.6 \mathrm{~dB}$ at a tilt angle of $+5^{\circ}$ for $70 \mathrm{kHz}$ and $-27.5 \mathrm{~dB}$ at a tilt angle of $+3^{\circ}$ for $120 \mathrm{kHz}$, respectively and the peak $T S$ at $120 \mathrm{kHz}$ was $2.1 \mathrm{~dB}$ higher that at $70 \mathrm{kHz}$.

Cuttlebone is bilaterally symmetrical in shape and derived from the juxtaposition of four parts: the outer cone, inner cone, phragmocone and spine. The dorsal surface of cuttlebone is evenly convex in outline but the anterior, median and posterior parts have slightly different curvatures (Neige 2003). Due to these morphological characteristics of cuttlebone, the dependence on the orientation of the cuttlebone TS is sensitive to the incidence direction (Figs. 7 and 8).

A comparison of the mean TS of cuttlefish with the mean TS of cuttlebone is shown in Fig. 10. A comparison of the measured and predicted contributions of cuttlebone to cuttlefish TS is shown in Table 3. In 


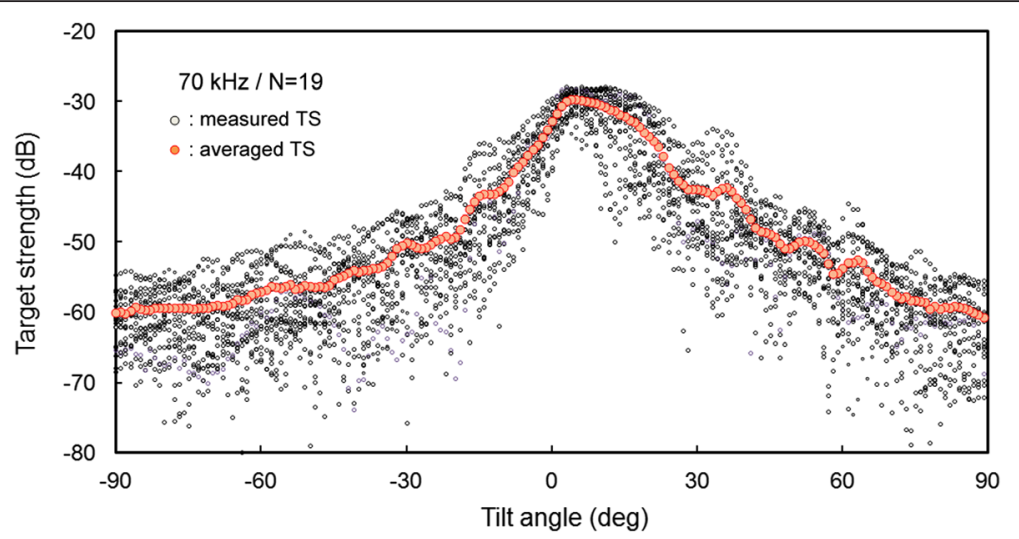

Fig. 7 TS functions (open circle) for all 19 cuttlebone measured as a function of tilt angle over the angle range $\left[-90^{\circ}, 90^{\circ}\right]$ from head-down to head-up orientations of the dorsal plane at $70 \mathrm{kHz}$. The tilt-averaged TS function (solid circle) was overlaid on the plot

Table 3, the contributions are indicated as the differences between the mean TS values that are described within the $95 \%$ confidence limits. In Fig. 10 and Table 3, the mean TS values measured using the combined dataset of all 38 specimens for 70 and $120 \mathrm{kHz}$ were $-32.76 \mathrm{~dB}$ for cuttlefish and $-32.87 \mathrm{~dB}$ for cuttlebone; i.e., the mean TS of cuttlefish was $0.11 \mathrm{~dB}$ higher than that of cuttlebone. On the other hand, the mean TS values predicted by regressions of the combined dataset of all 38 specimens for 70 and $120 \mathrm{kHz}$ were $-33.06 \mathrm{~dB}$ for cuttlefish and $-33.10 \mathrm{~dB}$ for cuttlebone; i.e., the mean TS of cuttlefish was $0.04 \mathrm{~dB}$ higher than that of cuttlebone. Accordingly, the contribution of cuttlebone to cuttlefish TS in the predicted results was slightly larger than in the measured results (Table 3). Furthermore, the measured mean TS values of cuttlefish and cuttlebone for a single frequency of $70 \mathrm{kHz}$ were -33.41 and $-33.60 \mathrm{~dB}$, respectively; a $0.19 \mathrm{~dB}$ difference. The measured mean TS values of cuttlefish and cuttlebone at a single frequency of $120 \mathrm{kHz}$ were -33.41 and $-33.60 \mathrm{~dB}$, respectively; a $0.19 \mathrm{~dB}$ difference. That is, the contribution of cuttlebone at $120 \mathrm{kHz}$ was $0.15 \mathrm{~dB}$ higher than at $70 \mathrm{kHz}$ (Table 3). On the other hand, the predicted mean TS values of cuttlefish and cuttlebone at a single frequency of $70 \mathrm{kHz}$ were -33.63 and $-33.71 \mathrm{~dB}$, respectively; a $0.08 \mathrm{~dB}$ difference. The predicted mean TS values of cuttlefish and cuttlebone at a single frequency of $120 \mathrm{kHz}$ were -32.55 and $-32.60 \mathrm{~dB}$, respectively, a $0.02 \mathrm{~dB}$ difference. That is, the contribution of cuttlebone at $120 \mathrm{kHz}$ was $0.06 \mathrm{~dB}$ higher than at $70 \mathrm{kHz}$ (Table 3).

The slopes of the regressions for a single frequency in this study were estimated to be 22.03 [95\% confidence interval (CI), $22.03 \pm 13.87, P<0.01]$ at $70 \mathrm{kHz}$ and 28.53 [ $95 \% \mathrm{CI}, 28.53 \pm 26.29, P<0.05$ ] at $120 \mathrm{kHz}$ [Eqs. (5) and (6)]. These results suggest that the mean TS of cuttlebone varies with approximately the square power of the length at 70 and $120 \mathrm{kHz}$. The intercept [95\% CI,

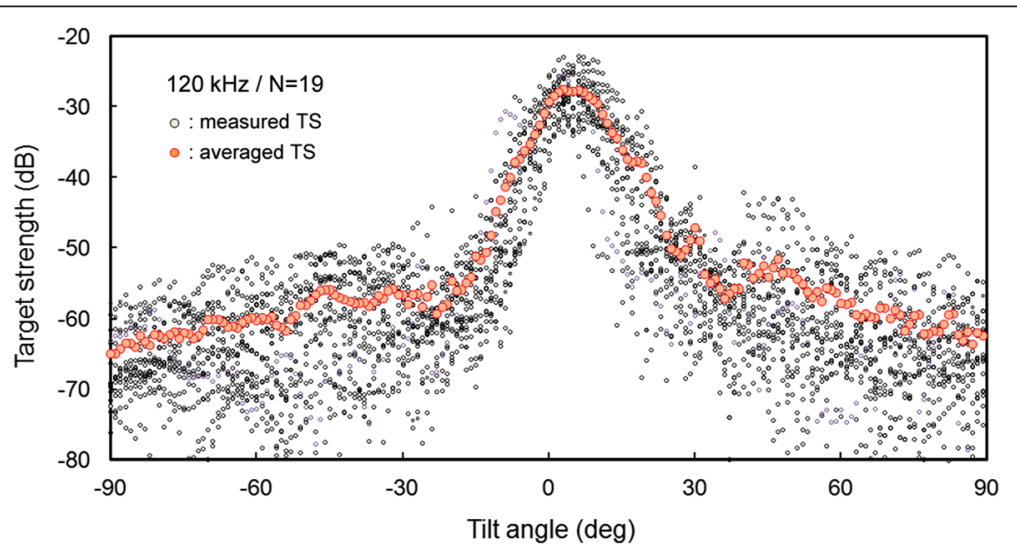

Fig. 8 TS functions (open circle) for all 19 cuttlebone measured as a function of tilt angle over the angle range [-90, $\left.90^{\circ}\right]$ from head-down to head-up orientations of the dorsal plane at $120 \mathrm{kHz}$. The tilt-averaged TS function (solid circle) was overlaid on the plot 


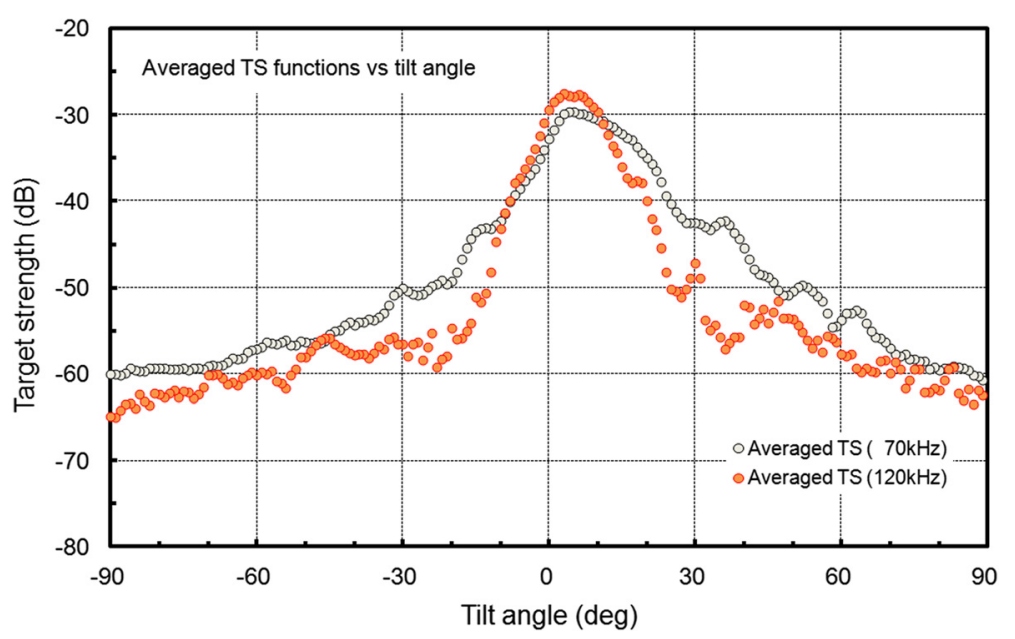

Fig. 9 Comparison of the tilt-averaged TS functions of cuttlebone obtained at 70 (open circle) and $120 \mathrm{kHz}$ (solid circle)

$-60.72 \pm 17.00 \mathrm{~dB}, P<0.01]$ of the regression line at $70 \mathrm{kHz}$ was $6.83 \mathrm{~dB}$ higher than at $120 \mathrm{kHz}$ [95\% CI, $-67.55 \pm 32.21 \mathrm{~dB}, P<0.01]$.

According to Simmonds and MacLennan (2005), the slope $(m)$ and intercept $(b)$ of cuttlefish vary widely versus fish species and commonly have values between 18 and 30 and 60 and 80, respectively. The slope and intercept in this study were within these ranges, although the determination coefficient $\left(r^{2}\right)$ indicated relatively low values of $r^{2}=0.40$ at $70 \mathrm{kHz}$ and $r^{2}=0.24$ at $120 \mathrm{kHz}$. Compared to our earlier study (Lee and Demer 2014), the slopes for cuttlebone were 2.64 at $70 \mathrm{kHz}$ and 12.06

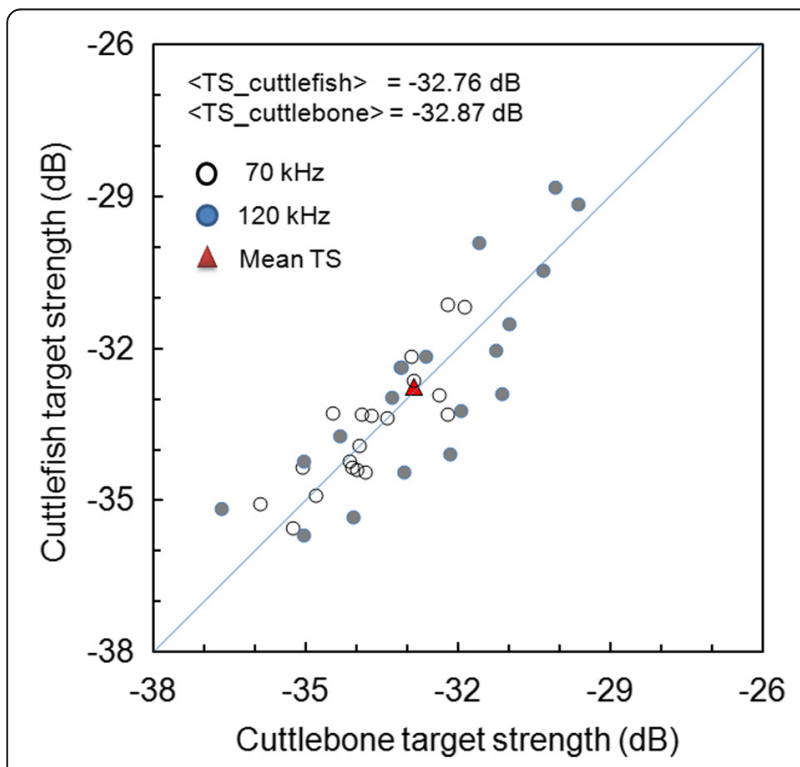

Fig. 10 Relationship between the measured TS values for all 38 specimen of cuttlebone and cuttlefish at 70 (open circle) and $120 \mathrm{kHz}$ (solid circle). Comparison of the mean $T S\left(\left\langle T S_{c}\right\rangle\right)$ of cuttlefish with the mean $T S\left(\left\langle T S_{b}\right\rangle\right)$ of cuttlebone was indicated as a solid triangle. Solid line indicates a reference line for comparison at $120 \mathrm{kHz}$, lower than those of cuttlefish, and the intercepts for cuttlebone were $3.31 \mathrm{~dB}$ at $70 \mathrm{kHz}$ and $15.41 \mathrm{~dB}$ at $120 \mathrm{kHz}$, higher than those of cuttlefish.

The chi-squared test of independence (CSTI, $99 \%$ confidence level) for the $T S_{m}$ and the $<T S_{b}>$ values at 70 and $120 \mathrm{kHz}$ showed that the $T S_{m}$ and the $<T S_{b}>$ values of cuttlebone at these two frequencies were independent $(P>0.01)$. Accordingly, to compare the $T S_{m}$ and the $\left\langle T S_{b}\right\rangle$ values measured at multiple frequencies, a non-dimensional representation may be used (McClatchie et al. 1996; McClatchie et al. 2003, this study). In this study, the 38 wavelength-normalized $T S_{m}$ and $<T S_{b}>$ values measured at two frequencies from 19 cuttlebones were compared and showed length-dependent scattering [e.g., Eqs. (10), (11) and (12)]. This formulation allowed twice the number of measurements (38 vs. 19) to be combined in the regression (Love 1969, 1971), which resulted in a considerably better fit $\left[r^{2}=0.88\right.$ in Eq. (10), $r^{2}=0.85$ in Eq. (11), and $r^{2}=0.85$ in Eq. (12)] (Fig. 5). The fitted coefficient $a, b$ and $c$ values for the regressions of Eqs. (4) and (11) were 24.86 [95 \% CI, $24.86 \pm 3.57, P<0.01$ ] , -4.86 [95\% CI, $-4.86 \pm 3.57, P<0.01$ ], and -22.58 [95\% CI, $-22.58 \pm 3.64, P<0.01]$, respectively. In Fig. 5 , the regression of the maximum $T S\left(T S_{m}\right)$, which is within the $95 \%$ confidence limit, was $\sim 5 \mathrm{~dB}$ higher than that of mean TS $\left.\left(<T S_{b}\right\rangle\right)$. Furthermore, at both frequencies, the contributions of the measured results were similar to those of the predicted results (Table 3 ). It is important to note that if the truncated limit of the tilt-angle distribution in the averaging operation by Foote's method (Foote 1980a, 1980b; Pena and Foote 2008) is controlled, the contribution may be altered to some extent.

The $T S$ of cuttlefish is expected to be markedly less depth-dependent than that of swimbladder fish because the buoyancy mechanism of cuttlebone, unlike the fish swimbladder, is almost independent of depth during 
Table 3 Comparison of the measured and predicted contributions of cuttlebone on the cuttlefish TS at 70 and $120 \mathrm{kHz}$. The contributions are indicated as the differences between the mean TS values that are described within the $95 \%$ confidence limits

\begin{tabular}{|c|c|c|c|c|c|c|}
\hline \multirow[t]{2}{*}{ Frequency $(\mathrm{kHz})$} & \multicolumn{3}{|c|}{ Measured results } & \multicolumn{3}{|l|}{ Predicted results } \\
\hline & Cuttlefish (dB) & Cuttlebone TS (dB) & Diff. (dB) & Cuttlefish TS (dB) & Cuttlebone TS (dB) & Diff. (dB) \\
\hline 70 & -33.41 & -33.60 & 0.19 & -33.63 & -33.71 & 0.08 \\
\hline 120 & -32.20 & -32.24 & 0.04 & -32.55 & -32.60 & 0.02 \\
\hline mean & -32.76 & -32.87 & 0.11 & -33.06 & -33.10 & 0.04 \\
\hline
\end{tabular}

vertical movements (Denton and Gilpin-Brown 1961; Denton et al. 1961; Denton and Taylor 1964). Knudsen and Gjelland (2004) reported that at least some coregonid species are capable of filling the swimbladder without access to the surface during the diel vertical migration and that TS did not decrease with depth. This swimbladder volume compensation in coregonids is compared to buoyancy regulation by the cuttlebone in cuttlefish. Generally, the change in the surface area of the swimbladder caused by the change in swimbladder volume affects $T S$, but because the dorsal surface of cuttlebone is unaffected by depth, the depth effect of cuttlebone on cuttlefish TS is not expected to be affected like the swimbladder of fish. Instead of having a flexible swimbladder like a fish, cuttlefish have a cuttlebone, which has a rigid structure, for buoyancy control. The cuttlebone is divided by many thin, chitinous partitions, which separate gas-filled anterior chambers and fluidfilled posterior chambers of approximately periodic microstructure (Denton and Gilpin-Brown 1961; Denton et al. 1961; Denton and Taylor 1964; Neige 2003; Cadman et al. 2010a, 2010b; Chen et al. 2011). Unlike the swim bladder of fish, cuttlebone is unpressurized, so its volume is not altered markedly as the animal changes depth (Denton and Gilpin-Brown 1961; Denton et al. 1961; Denton and Taylor 1964), and no adjustments to the buoyancy system are necessary during vertical movements (Sherrard 2000).

Generally, the fish TS is proportional to the difference in density between the insonified fish target and the surrounding water (Simmonds and MacLennan 2005), and the main source of backscatter is expected to be proportional to the size of the swimbladder, which accounts for at least $90 \%$ of echo energy (Foote 1980a, 1980b, 1985; Foote and Ona 1985). The impedance of gas-filled organs, such as the swimbladder and cuttlebone, differs considerably from that of seawater and other fish tissues, and the scattering contribution of cuttlebone is comparable to that of an air-filled swimbladder. However, in cuttlefish, the problems of pressure changes are avoided by enclosing the gas in the cuttlebone, the volume of which is unaffected by changes in depth and which contains many chambers, some filled with gas and some with liquid. The overall density of the cuttlebone varies between $\sim 0.5$ and 0.7 , and is controlled by regulating its liquid content (Denton and Gilpin-Brown 1961; Denton et al. 1961; Denton and Taylor 1964). Accordingly, the acoustic scattering by cuttlefish is expected to fluctuate in proportion with changes in the overall density of cuttlebone. Madsen et al. (2007) reported that the muscular mantle and fins of the common squid are the dominant scatterers, and that the hard parts-such as beak, eyes and pen-contribute little to the TS of squid, at least for frequencies representative of the clicks of most teutophageous toothed whales. This suggests that the acoustic interference of the muscular mantle, fins and cuttlebone in freely swimming cuttlefish are complexly generated based on frequency.

In this study, the TS of cuttlebone was measured and analyzed as a function of length only; however, the TS may actually be more sensitive to the dorsal surface area (or volume) of cuttlebone rather than the length. Based on a comparison of the TS- $L$ relationships for the corresponding cuttlebone and live cuttlefish for 19 specimens, the contribution of cuttlebone to the backscattering echo strength of cuttlefish was estimated to be at least $99 \%$. Moreover, the cuttlebone volume (or surface area) may have a greater influence on cuttlefish TS than the length, because the proportion of cuttlebone volume as a fraction of the total body volume of cuttlefish ( 9.3 \%) is almost twofold that of the swimbladder of fish $(\sim 5 \%)$ (Denton and Gilpin-Brown 1961; Denton et al. 1961; Denton and Taylor 1964). The relationship between cuttlebone volume and cuttlefish TS may be complicated by the complex microstructure of the gas-filled internal shell of the cuttlebone. However, the effects of the morphological and material parameters of cuttlebone-such as length, width, height, density change and curvature of the dorsal surface-must be analyzed to quantitatively estimate the influence of cuttlebone on cuttlefish TS. This will be the subject of a future study.

\section{Conclusions}

The mean TS values of cuttlebone were 0.19 and $0.04 \mathrm{~dB}$ lower than those of cuttlefish at 70 and $120 \mathrm{kHz}$, respectively. The contribution of cuttlebone to the cuttlefish TS determined by the measured results was slightly greater than that by the predicted results. From these results, we concluded that cuttlebone is responsible for the TS of 
cuttlefish, and the contribution is estimated to be at least $99 \%$ of the total echo strength.

\section{Competing interests}

The author declares that he has no competing interests.

\section{Author's contribution}

$\mathrm{DL}$ carried out the experiment, wrote the manuscripts and performed the data analysis. The author approved the final version of the manuscript.

\section{Acknowledgments}

This work was supported by a Research Grant of Pukyong National University (2015 year).

Received: 18 March 2016 Accepted: 1 April 2016

Published online: 12 April 2016

\section{References}

Benoit-Bird KJ, Gilly WF, Au WWL, Mate B. Controlled and in situ target s strengths of the jumbo squid Dosidicus gigas and identification of potential acoustic scattering sources. J Acoust Soc Am. 2008;123:1318-28.

Cadman J, Chen Y, Zhou S, Li Q. Creating biomaterials inspired by the microstructure of cuttlebone. Mater Sci Forum. 2010a;654:2229-32.

Cadman J, Zhou S, Chen Y, Li W, Appleyard R, Li Q. Characterization of cuttlebone for a biomimetic design of cellular structures. Acta Mech Sin. 2010b;26:27-35.

Chen Y, Cadman J, Zhou S, Li Q. Computer-aided design and fabrication of biomimetic materials and scaffold micro-structures. Adv Mater Res. 2011;213:628-32.

Conti SG, Demer DA. Wide-bandwidth acoustical characterization of anchovy and sardine from reverberation measurements in an echoic tank. ICES J Mar Sci. 2003:60:617-24

Demer DA, Martin LV. Zooplankton target strength: Volumetric or areal depenpence? J Acoust Soc Am. 1995;98:1111-8.

Denton EJ, Gilpin-Brown JB. The buoyancy of the cuttlefish, Sepia Officinalis (L.). J Mar Bio Ass UK. 1961;41:319-42.

Denton EJ, Taylor DW. The composition of gas in the chambers of the cuttlebone of Sepia Officinalis. J Mar Bio Ass UK. 1964:44:203-7.

Denton EJ, Gilpin-Brown JB, Howarth JV. The osmotic mechanism of the cuttlebone. J Mar Bio Ass UK. 1961:41:351-64.

Fnney JL, Robertson GN, McGee CAS, Smith FM, Croll RP. Structure and autonomic innervations of the swim bladder in the zebrafish (Danio rerio). J Comp Neurol. 2006:495:587-606.

Foote KG. Averaging of fish targets strength functions. J Acoust Soc Am. 1980a; 67:504-15.

Foote KG. The importance of the swimbladder in acoustic scattering by fish: A comparison of gadoid and mackerel target strengths. J Acoust Soc Am. 1980b;67:2084-9.

Foote KG. Rather-high-frequency sound scattering by swimbladdered fish. J Acoust Soc Am. 1985;78:688-700.

Foote KG. Fish target strengths for use in echo integrator surveys. J Acoust Soc Am. 1987:82:981-7.

Foote KG. Range compensation for backscattering measurements in the difference frequency nearfield of a parametric sonar. J Acoust Soc Am. 2012; 131:3698-709.

Foote KG, Ona E. Swimbladder cross sections and acoustic target strengths of 13 pollack and 2 saithe. FiskDir Skr Ser HavUnders. 1985;18:1-57.

Goddard GC, Welsby VG. The acoustic target strength of live fish. J Cons Int Explor Mer. 1986;42:197-211.

Horne JK. Acoustic ontogeny of a teleost. J Fish Biol. 2008;73:1444-63.

Imaizumi T, Furusawa M, Akamatsu T, Nishimori Y. Measuring the target strength spectra of fish using dolphin-like short broadband sonar signals. J Acoust Soc Am. 2008;124:3440-9.

Kang D, Mukai T, lida K, Hwang DJ, Myoung JK. The influence of tilt angle on the acoustic target strength of the Japanese common squid (Todarodes pacificus). ICES J Mar Sci. 2005;62:779-89.

Knudsen FR, Gjelland KØ. Hydroacoustic observations indicating swimbladder volume compensation during the diel vertical migration in coregonids (Coregonus lavaretus and Coregonus albula). Fish Res. 2004;66:337-41.

Lee DJ. Target strength measurements of black rockfish, goldeye rockfish and black scraper using a 70-kHz split beam echo sounder (in Japanese with English abstract). Nippon Suisan Gakkaishi. 2006;72:644-50.
Lee DJ, Demer DA. Target strength measurements of live golden cuttlefish (Sepia esculenta) at 70 and $120 \mathrm{kHz}$. Fish Aquat Sci. 2014;17:361-7.

Love RH. An empirical equation for the determination of the maximum sideaspect target strength of an individual fish. Naval Oceanographic Office. AD849034. 1969. p. 1-17.

Love RH. Measurements of fish target strength: a review. Fish Bull. 1971;69:703-15.

Madsen PT, Wilson M, Johnson M, Hanlon RT, Bocconcelli A, Aguilar de Soto N, et al. Clicking for calamari: toothed whales can echolocate squid Loligo pealeii. Aquat Biol. 2007;1:141-50.

McClatchie S, Alsop J, Coombs RF. A re-evaluation of relationships between fish size, acoustic frequency, and target strength. ICES J Mar Sci. 1996;53:780-91.

McClatchie S, McCauley GJ, Coombs RF. A requiem for the use of $20 \log _{10}$ Length for acoustic target strength with special reference to deep-sea fishes. ICES J Mar Sci. 2003;60:419-28.

Midtvedt D, Sobko T, Midtvedt T. Nitric oxide (NO) gas present in the swim bladder of cod (Gadus morhua). Microb Ecol Health Dis. 2007;19:150-2.

Neige P. Combining disparity with diversity to study the biogeographic pattern of sepiida. Berliner Paläobiol Abh. 2003;3:189-97.

Pena H, Foote KG. Modelling the target strength of Trachurus symmetricus murphyi based on high-resolution swimbladder morphometry using an MRI scanner. ICES J Mar Sci. 2008;65:1751-61.

Sawada K, Uchikawa K, Matsuura T, Sugisaki H, Amakasu K, Abe K. In situ and Ex situ target strength measurement of mesopelagic lanternfish, Diaphus theta (Family mactophidae). J Mar Sci Technol. 2011;19:302-11.

Sherrard KM. Cuttlebone morphology limits habitat depth in eleven species Sepia (Cephalopoda: Sepiidae). Biol Bull. 2000:198:404-14.

Simmonds J, MacLennan D. Fisheries Acoustics. Oxford: Blackwell Publishing; 2005.

Sunardi, Yudhana A, Din J, Bidin R, Hassan R. Swimbladder on fish target strength. Telkomnika. 2008;6:139-44.

Webber DM, Aitken JP, O'Dor RK. Costs of locomotion and vertic dynamics of cephalopods and fish. Physiol Biochem Zool. 2000;73:651-62.

\section{Submit your next manuscript to BioMed Central and we will help you at every step:}

- We accept pre-submission inquiries

- Our selector tool helps you to find the most relevant journal

- We provide round the clock customer support

- Convenient online submission

- Thorough peer review

- Inclusion in PubMed and all major indexing services

- Maximum visibility for your research

Submit your manuscript at www.biomedcentral.com/submit
Biomed Central 